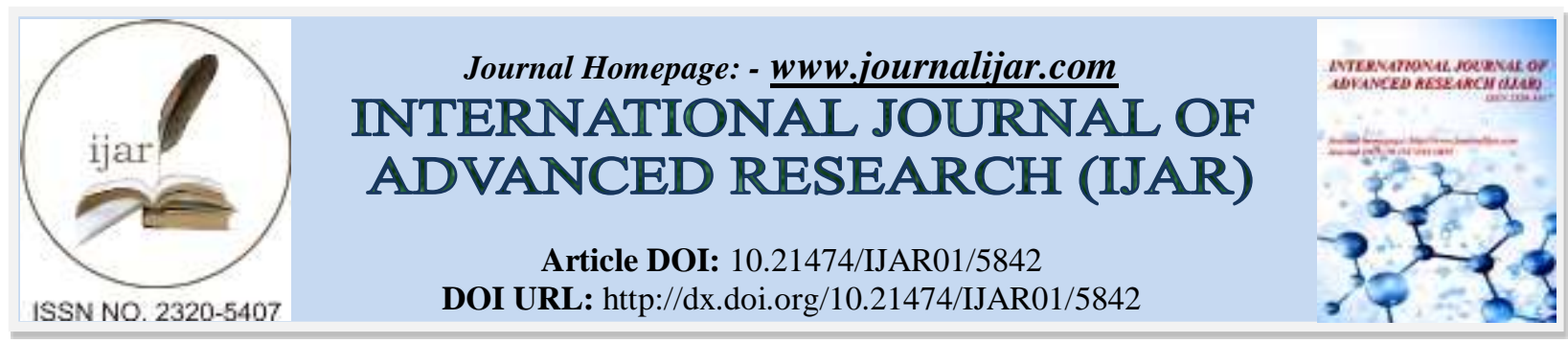

RESEARCH ARTICLE

\title{
PROBLEM SOLVING ABILITY AND ACADEMIC ACHIEVEMENT OF HIGHER SECONDARY STUDENTS.
}

Dr. M. Kanmani ${ }^{1}$ and N. Nagarathinam ${ }^{2}$.

1. Associate Professor, Department of Educational Technology, TNTEU, Chennai. Tamilnadu.

2. Ph.D , Research Scholar, Department of Educational Technology, TNTEU, Chennai. Tamilnadu.

\section{Manuscript Info}

Manuscript History

Received: 12 September 2017

Final Accepted: 14 October 2017

Published: November 2017

\begin{abstract}
Problem solving has a special importance in the study of mathematics. The primary goal of mathematics teaching and learning is to develop the ability to solve a wide variety of complex mathematics problems. A problem is an obstruction of some sort to the attainment of an objective, a sort of difficulty which does not enable the individual to reach a goal easily. The present study aims to find out the relationship between problem solving ability and achievement in mathematics of higher secondary students. Fifty five, higher secondary students were randomly selected as sample. Survey method was adopted for the study. The data was collected using a test on problem solving ability (PSA). The t-test, chi-square test and pearson's product moment correlation were applied to test the hypotheses. Interpretation were drawn based on the findings. Problem solving ability of the higher secondary students was found to be an average and there was a high positive correlation between problem solving ability and achievement in mathematics.
\end{abstract}

Copy Right, IJAR, 2017,. All rights reserved.

\section{Introduction:-}

Today's society is required to produce well-educated people who have the ability to adapt themselves to the rapidly changing and developing world. Social, economic, political and technological changes in social structure have become more complicated. Our times are marked by the speed with which change occurs and this leaves an individual facing new problems and challenges each day. As in all scientific processes, problem solving should be realised in our daily life.

It is common knowledge that all through history people have solved or attempted to solve problems using the trial and error method. The process of problem solving begins with the perception of the problem and finishes with evaluation. Even though problem solving shows differences according to the problems and the individuals, the main steps of problem solving are problem understanding, planning for solution, application of plan and evaluating results (Senemoglu, 2005).

Mason (2003) further expressed that students' mathematics and mathematical problem-solving beliefs are important, noting that as problem-solving beliefs increase, their achievements will increase accordingly, because mathematics plays a vital role in the economic and social development of a country which is the basis for all science and 
technology. Mathematics is the queen of all sciences and the backbone of civilization. Learning of mathematics involves making connections between concrete mathematical experiences and abstract thinking processes.

\section{Review of Related literature:-}

Biswajit Behera (2009) studied the problem solving skills in mathematics learning. The study revealed that the mean difference between high ability and low ability groups, between boys and girls and within each ability group is quite large. Students with high mathematical ability are far superior in mathematical problem solving skill to their counter parts in the lower ability irrespective of their gender.

Sakom Pimta, et al (2009) studied the factors influencing mathematic problem-solving ability of sixth grade students. This study revealed that teachers' behaviours took both direct and indirect effects on the students' mathematic problem solving. The teachers are supposed to study the methods to develop this ability deeply and then bring them to manage the activities in class that encourage students to be enthusiastic to learn and have good attitude toward mathematic learning or to get students' concentration.

The relationships between mathematical knowledge and problem-solving behaviours in the contexts of solving an insight geometry problem, posing algebraic problems and calculus exploration was studied by Boris Koichu (2010). The findings of the study revealed that advanced mathematical knowledge and advanced problem-solving behaviours do not always support each other. More advanced behaviours were observed when the student worked within her conceptual-embodied mathematical world, and less advanced ones when worked within the symbolic and formalaxiomatic worlds.

Bulent Guven, Buket Ozum Cabakcor (2013) studied the factors influencing mathematical problem-solving achievement of seventh grade turkish students. This study revealed that the difference between male and female students' problem-solving achievement is not statistically significant.

\section{Need and significance of the study:-}

Mathematical problems play an important role in helping students to participate in problem-solving activities and stimulate their learning abilities. The problems should be challenging enough for students to solve in order to enhance their knowledge and comprehension. This type of activity develops students' curiosity in solving mathematics problems and successfully enhances their cognitive processes

\section{Objectives of the study:-}

1. To find out the level of problem solving ability and achievement in mathematics of higher secondary students.

2. To find out whether there is any significant relationship between problem solving ability and academic achievement in mathematics of higher secondary students.

3. To find out whether there is any significant association in achievement in mathematics of higher secondary students with respect to educational qualification of fathers and mothers.

4. To find out whether there is any significant association in problem solving ability of higher secondary students with respect to educational qualification of fathers and mothers.

5. To find out whether there is any significant difference in achievement in mathematics of higher secondary students with respect to

1. Gender

2. Group of study

3. Type of school

To find out whether there is any significant difference in problem solving ability of higher secondary students with respect to

1. Gender

2. Group of study

3. Type of school

\section{Methodology:-}

Survey method was adapted for the study 


\section{Sample Selection:-}

Fifty five higher secondary students were selected using random sampling technique from various schools of Kanchipuram district for the study.

Research Instruments Used:-

A test on Problem Solving Ability Test (PSAT) was constructed and validate by Dr.M.Kanmani and Nagarathinam (2016).

Description of the tool:-

The draft tool contained fifty items to assess the problem solving ability of higher secondary students.

Validity:-

Content validity was found using item-wise analysis. The items which have difficulty value between 40 and 60 , and discrimination index $\geq 0.4$ were selected. Hence, twenty six items were selected.

Reliability:-

Split-half technique was used to establish the coefficient of reliability of PSA test and it was found to be 0.9. Hence the tool is highly reliable.

\section{Scoring procedure:-}

One mark was awarded for correct answer and no mark was awarded for wrong answer.

\section{Statistical techniques used:-}

Critical ratio (t-test), Chi-Square test and Pearson's product moment correlation techniques were used for analyzing the data.

\section{Hypothesis testing:-}

Hypothesis 1:- There is no significant relationship between problem solving ability and achievement in mathematics of higher secondary students.

\begin{tabular}{|c|c|c|}
\hline Variables & ' $\mathbf{r}$ & Table value \\
\hline Problem solving ability and Achievement in mathematics & 0.97 & 0.254 \\
\hline
\end{tabular}

(at $5 \%$ level of significance the table value ' $r$ ' is 0.254 )

It is inferred from the above table that the calculated value of ' $r$ ' $(0.97)$ is greater than the table value of ' $r$ ' $(0.254)$ at $5 \%$ level of significance. Hence the null hypothesis is rejected. Therefore, there is a significant relationship between problem solving ability and achievement in mathematics of higher secondary students. Further, it can be stated that there exist high positive correlation between problem solving ability and achievement in mathematics of higher secondary students.

Hypothesis 2:- There is no significant association between achievement in mathematics of higher secondary students with respect to their fathers' and mothers' educational qualification.

\begin{tabular}{|c|c|c|c|c|c|c|}
\hline \multirow{2}{*}{$\begin{array}{c}\text { Achievement } \\
\text { Categories }\end{array}$} & \multicolumn{3}{|c|}{ Mothers' qualification } & \multicolumn{3}{c|}{ Fathers' qualification } \\
\cline { 2 - 7 } & Low & Average & High & Low & Average & High \\
\hline Illiterate & $1(1.27)$ & $3(2.63)$ & $1(1.09)$ & $1(0.25)$ & $0(0.52)$ & $0(0.21)$ \\
\hline $10^{\text {th }}$ & $4(4.32)$ & $10(8.96)$ & $3(3.7)$ & $7(4.58)$ & $9(9.49)$ & $2(3.92)$ \\
\hline $12^{\text {th }}$ & $4(4.32)$ & $8(8.96)$ & $5(3.7)$ & $5(4.83)$ & $12(10.01)$ & $2(4.14)$ \\
\hline UG & $3(2.8)$ & $5(5.8)$ & $3(2.4)$ & $1(3.3)$ & $8(6.85)$ & $4(2.83)$ \\
\hline PG & $2(1.27)$ & $3(2.63)$ & $0(1.09)$ & $0(1.01)$ & $0(2.1)$ & $4(0.87)$ \\
\hline Chi-square ' $\chi^{2}$, & \multicolumn{3}{|c|}{$\mathbf{0 . 9 4 5}$} & \multicolumn{3}{c}{$\mathbf{0 . 0 2 9}$} \\
\hline
\end{tabular}

(at $5 \%$ level the table of significance value ' $\chi^{2}$ ' is 15.51 )

It is inferred from the above table that the calculated values of ' $\chi^{2}$ ' $(0.945$ and 0.029$)$ are less than the table value 15.51 at $5 \%$ level of significance. Hence the null hypothesis is accepted. Therefore, fathers' and mothers' educational qualification of higher secondary students did not associate significantly in achievement in mathematics. 
Hypothesis 3:- There is no significant association between problem solving ability of higher secondary students with respect to their fathers' and mothers' educational qualifications.

\begin{tabular}{|c|c|c|c|c|c|c|}
\hline \multirow{2}{*}{$\begin{array}{r}\text { Problem solving } \\
\text { ability } \\
\text { Categories }\end{array}$} & \multicolumn{3}{|c|}{ Mothers' qualification } & \multicolumn{3}{|c|}{ Fathers' qualification } \\
\hline & Low & Average & High & Low & Average & High \\
\hline Illiterate & $0(0.81)$ & $5(3.45)$ & $0(0.72)$ & $1(0.16)$ & $0(0.69)$ & $0(0.14)$ \\
\hline $10^{\text {th }}$ & $6(2.78)$ & $9(11.74)$ & $2(2.47)$ & $3(2.94)$ & $13(12.43)$ & $2(2.76)$ \\
\hline $12^{\text {th }}$ & $1(2.78)$ & $12(11.74)$ & $4(2.47)$ & $4(3.1)$ & 14(13.12) & $(2.31)$ \\
\hline UG & $2(1.8)$ & $9(7.6)$ & $0(1.6)$ & $1(2.12)$ & $11(8.98)$ & $(1.89)$ \\
\hline PG & $0(0.81)$ & $3(3.45)$ & $2(0.72)$ & $0(0.65)$ & $0(2.76)$ & $(0.52)$ \\
\hline Chi-square ' $\chi^{2}$, & \multicolumn{3}{|c|}{0.087} & \multicolumn{3}{|c|}{0.01} \\
\hline
\end{tabular}

(at $5 \%$ level of significance the table value ' $\chi$ ' ' is 15.51 )

It is inferred from the above table that the calculated values of ' $\chi^{2}$ ' $(0.087$ and 0.01$)$ are less than the table value 15.51 at 5\% level of significance. Hence the null hypothesis is accepted. Therefore, fathers' and mothers' educational qualification of higher secondary students did not associate significantly in problem solving ability in mathematics.

Hypothesis 4:- There is no significant difference between boys and girls higher secondary students' achievement in mathematics.

\begin{tabular}{|c|c|c|c|c|}
\hline Gender & N & Mean & S.D & t \\
\hline Boys & 30 & 16.3 & 4.61 & 0.397 \\
\hline Girls & 25 & 17.52 & 4.28 & \\
\hline
\end{tabular}

(at $5 \%$ level of significance the table value ' $\mathrm{t}$ ' is 1.67)

It is inferred from the above table that the calculated value ' $t$ ' (0.397) is less than the table value of ' $t$ ' (1.67) at $5 \%$ level of significance. Hence the null hypothesis is accepted. Therefore, boys and girls higher secondary students' do not differ significantly in achievement in mathematics.

Hypothesis 5:- There is no significant difference in achievement in mathematics of higher secondary students with respect to group chosen.

\begin{tabular}{|c|c|c|c|c|}
\hline Group & N & Mean & S.D & t \\
\hline Bio- Mathematics & 29 & 16.1 & 3.69 & \multirow{2}{*}{0.346} \\
\hline Computer science-Mathematics & 26 & 17.96 & 5.03 & \\
\hline
\end{tabular}

(at $5 \%$ level of significance the table value ' $t$ ' is 1.67)

It is inferred from the above table that the calculated value ' $t$ ' (0.346) is less than the table value of ' $t$ ' (1.67) at $5 \%$ level of significance. Hence the null hypothesis is accepted. Therefore, higher secondary students whose major group was biology-mathematics and computer science - mathematics did not differ significantly in achievement in mathematics.

Hypothesis 6:- There is no significant difference in achievement in mathematics of higher secondary students with respect to type of school.

\begin{tabular}{|c|c|c|c|c|}
\hline Type of School & N & Mean & S.D & t \\
\hline Government Aided School & 19 & 17.52 & 4.42 & \multirow{2}{*}{0.46} \\
\hline Self Financing School & 36 & 16.69 & 4.5 & \\
\hline
\end{tabular}

(at $5 \%$ level of significance the table value ' $t$ ' is 1.67 )

It is inferred from the above table that the calculated value ' $t$ ' $(0.46)$ is less than the table value of ' $t$ ' (1.67) at $5 \%$ level of significance. Hence the null hypothesis is accepted. Therefore, higher secondary students studying in government aided and self financing schools did not differ significantly in achievement in mathematics.

Hypothesis 7:- There is no significant difference between boys and girls higher secondary students' problem solving ability in mathematics.

\begin{tabular}{|c|c|c|c|c|}
\hline Gender & N & Mean & S.D & t \\
\hline
\end{tabular}




\begin{tabular}{|c|c|c|c|c|}
\hline Boys & 30 & 23.5 & 4.39 & 0.45 \\
\hline Girls & 25 & 24.16 & 6.43 & \\
\hline
\end{tabular}

(at $5 \%$ level of significance the table value ' $t$ ' is 1.67 )

It is inferred from the above table that the calculated value ' $t$ ' $(0.45)$ is less than the table value of ' $t$ ' $(1.67)$ at $5 \%$ level of significance. Hence the null hypothesis is accepted. Therefore, boys and girls higher secondary students do not differ significantly in their problem solving ability in mathematics.

Hypothesis 8:- There is no significant difference in problem solving ability in mathematics of higher secondary students with respect to group chosen.

\begin{tabular}{|c|c|c|c|c|}
\hline Group & N & Mean & S.D & t \\
\hline Biology- Mathematics & 29 & 24.06 & 5.92 & 0.347 \\
\hline Computer science-Mathematics & 26 & 23.5 & 4.78 & \\
\hline
\end{tabular}

(at 5\% level of significance the table value ' $t$ ' is 1.67 )

It is inferred from the above table that the calculated value ' $t$ ' $(0.347)$ is less than the table value of ' $t$ ' $(1.67)$ at $5 \%$ level of significance. Hence the null hypothesis is accepted. Therefore, higher secondary students whose major group was biology-mathematics and computer science - mathematics did not differ significantly in their problem solving ability in mathematics.

Hypothesis 9:- There is no significant difference in problem solving ability in mathematics of higher secondary students with respect to type of school.

\begin{tabular}{|c|c|c|c|c|}
\hline Type of School & N & Mean & S.D & t \\
\hline Government Aided School & 19 & 23.78 & 5.33 & 0.49 \\
\hline Self Financing School & 36 & 23.8 & 5.47 & \\
\hline
\end{tabular}

(at $5 \%$ level of significance the table value ' $t$ ' is 1.67 )

It is inferred from the above table that the calculated value ' $t$ ' $(0.49)$ is less than the table value of ' $t$ ' $(1.67)$ at $5 \%$ level of significance. Hence the null hypothesis is accepted. Therefore, higher secondary students studying in government aided and self financing schools did not differ significantly in their problem solving ability in mathematics.

Findings:-

1. 65.5 percentage of higher secondary students had an average level of problem solving ability and achievement in mathematics.

2. There is high positive correlation between problem solving ability and achievement in mathematics of higher secondary students.

3. Fathers' and mothers' educational qualification of higher secondary students did not associate significantly in problem solving ability and achievement in mathematics.

4. Boys and girls higher secondary students do not differ significantly in problem solving ability and achievement in mathematics.

5. Higher secondary students whose major group was biology-mathematics and computer science - mathematics did not differ significantly in problem solving ability and achievement in mathematics.

6. Higher secondary students studying in government aided and self financing schools did not differ significantly in problem solving ability and achievement in mathematics.

\section{Result discussion:-}

The study revealed that 65.5 percentage of higher secondary students had an average level of problem solving ability and achievement in mathematics. This result coincides with the study result of Kavitha Madhusudan (2009) and contradicts with P.N.Nataraj \& Manjula (2012) and P.P.Singhal \& Aswini Kumar (2014). (ii). There was high positive correlation exists between problem solving ability and achievement in mathematics of higher secondary students, which coincides with the study result of Kavitha Madhusudan (2009) and Singhal.P.P \& Aswini Kumar (2014) and contradicts with P.N.Nataraj and Manjula (2012). 
Fathers' and mothers' educational qualification of higher secondary students' did associate significantly in problem solving ability and achievement in mathematics, which coincides with the study result of P.N.Nataraj \& Manjula (2012). (iv). Boys and girls higher secondary students do not differ significantly in problem solving ability and achievement in mathematics, which coincides with the study result of Nand Kishor Choudhary (2015) and Bulent Guven, Buket Ozum Cabakcor (2013) and contradicts with P.N.Nataraj and Manjula (2012). (v). Higher secondary students studying in government aided and self financing schools did not differ significantly in problem solving ability and achievement in mathematics, which contradicts with the study result of P.N.Nataraj and Manjula (2012).

\section{Educational implications:-}

There is high positive correlation was exist between problem solving ability and achievement in mathematics of higher secondary students. For improving problem solving ability among students, teachers can adopt various teaching techniques like heuristic method, blended learning and experimental methods. Special lectures on complex concepts may be arranged to facilitates their learning, guidance programme can be provided in schools according to their knowledge level.

\section{Conclusion:-}

The purpose of the present study was to find the level of problem solving ability in mathematics of higher secondary students. The study result may be useful in the field of education, which may serve as data base for further research.

\section{Bibliography:-}

1. Bulent Guven, Buket Ozum Cabakcor (2013), "Factors Influencing Mathematical Problem-Solving Achievement of Seventh Grade Turkish Students", https://www.researchgate.net, retrieved on 14.10.17.

2. Boris Koichu, (2010), "On the Relationship between Mathematical Knowledge and Problem-Solving Behaviours", https://www.researchgate.net, retrieved on 14.10.17.

3. Biswajit Behera (2009), "Problem Solving Skills in Mathematics Learning", https://www.researchgate.net, retrieved on 14.10.17.

4. Kavitha Madhusudan (2009), "Interaction Effect of Mathematical Creativity, Intelligence and Problem Solving Ability on Achievement in Mathematics of IX Standard Students of Bangalore District", ph.d thesis, 2015, pp 283.

5. Nand kishor choudhary (2015), "Study of Problem Solving Ability among Senior Secondary School Students", www.worldwidejournals.com, retrieved on 08.06.17

6. Nataraj.P.N, Manjula (2012) "A Study of Problem Solving Ability among the Matriculation School Students", www.ijter.com, retrieved on 18.10.17.

7. Prakash Chandra Jena (2014), "Cognitive Styles and Problem Solving Ability of Undergraduate Students", www.ijepr.org, retrieved on 20.09.17.

8. Robert McIntosh (2000), "Teaching Mathematical Problem Solving: Implementing the Vision", www.cimm.urc.ac.cr, retrieved on 16.07.17, Mathematics and Science Education Center, 2000, pp.15-22.

9. Sakom Pimta, Sombat Tayruakham, Prasart Nuangchalerm (2009) "Factors Influencing Mathematic Problem-Solving Ability of Sixth Grade Students", https://www.researchgate.net, retrieved on 14.09.17.

10. Singhal.P.P, Ashwani Kumar (2014), "Study of Academic Achievement in Relation to Problem Solving Ability", www.ijrssh.com, retrieved on 17.10.17. 